\title{
Effects of extraneous fear arousal and birth order on attitude change
}

CLYDE HENDRICK and RICHARD BORDEN, Kent State University, Kent, Ohio 44240

This study explored the effects of extraneous fear arousal on susceptibility to a persuasive communication. Under the guise of participating in a psychophysiology experiment, Ss were led to believe that they would receive a series of either strong or weak shocks. Ss were then induced to participate in a "second experiment" while waiting for E to prepare his equipment. The second experiment consisted of reading a persuasive communication and completing several questionnaires. Results for attitude change for males showed a Fear by Birth Order interaction. Results for females showed only a main effect of fear arousal, with more persuasion occurring in the low-fear than in the high-fear conditions.

The effect of fear-arousing communications on attitude change has been an active and controversial area of research since Janis \& Feshbach (1953) reported an inverse relationship between strength of the fear appeal and attitude change. Most of the studies since then have found either a direct relationship (McGuire, 1966, 1969) or no relationship. This area of research is important for both theoretical and practical reasons, although the methodology of the experiments causes difficulties in interpretation of the data. The major problem is that the manipulation of fear has always been confounded with changes in the content of the persuasive communications. Variation in the strength of the fear appeal necessarily requires such variation in content. Thus, in all the studies, it is unclear whether differential persuasion was due to differences in fear or to differences in informational content of different messages.

A solution to this problem requires that fear be manipulated independently of communication content. Two recent studies have taken this approach. Helmreich, Kuiken, \& Collins (1968) presented a communication to Naval recruits under conditions of high and low credibility, and high and low extraneous fear, and then measured their attitude on the issue. A high-fear group was exposed to the communication just prior to entering a gas chamber to test a new gas mask. A low-fear group was exposed to the communication in their barracks. The results showed that $S s$ in the high-fear condition were more persuaded than were Ss in the low-fear condition. Birth order of the Ss interacted with fear. In the low-fear condition, there was no difference between first born and later born Ss. However, in the high-fear condition, later borns showed more attitude change than did first borns. Variation in communicator credibility had no significant effects.

However, in a second experiment, Sigall \& Helmreich (1969) manipulated credibility and fear in a manner irrelevant to the content of the communication and found that communicator credibility did interact with level of fear arousal. In contrast to the first experiment, there were no effects attributable to birth order.

The present study was conducted in an attempt to resolve the ambiguity in the results of these two studies and to extend their generality. Both of Helmreich's studies used males as Ss. In the present experiment, both males and femalexwere used, as well as two different communications.

\section{METHOD}

Twenty-four male and 24 female students in an introductory psychology section participated individually in a "human psychophysiology" experiment. When a $S$ arrived for the experiment, he was seated in front of a polygraph and a complicated relay rack. A male E explained his interest in obtaining physiological measures. He attached several electrodes to the $S$ and then took measures of heart rate and blood pressure. During this procedure, the $\mathrm{S}$ was given a shock that was barely perceptible. After a few minutes of such pseudomeasurement, the $E$ said that he would now use the initial information to calibrate his equipment for further extended measurement, and that this calibration would take $15 \mathrm{~min}$. So that the $S$ would not have to waste his time during the calibration, the $E$ explained that he had arranged for the $S$ to participate in another brief experiment being conducted down the hall. After the $S$ agreed to this arrangement, the fear manipulation was introduced. In the low-fear condition, a $S$ was told that when he returned he would be given a series of very mild shocks just like the barely perceptible shock he had received earlier and that his physiological responses to the shocks would be taken. A $S$ in the high-fear condition was told that when he returned he would be given a series of very intense shocks that would be extremely painful al though they would not cause any permanent damage. The $E$ said that such shocks were absolutely necessary to test the limits of the S's physiological responses.

After the fear induction, the $\mathrm{E}$ escorted the $S$ down the hall to another room where a second E (a female) was waiting." A sign on the door labeled it as the "Study Effectiveness Research Project." The first $E$ introduced the $S$ to the second $E$ and reminded the $S$ to return to the psychophysiology experiment when finished with the second experiment. The $S$ was seated, and the second E explained the (purported) nature of her experiment. She stated that the experiment was one of a series designed to determine the most effective conditions under which students should study. The present experiment was concerned with the effect of quiet vs noise background on study effectiveness. The $\mathrm{S}$ was told that he was in the quiet condition and would wear earphones while reading an article. After reading, he would complete several questionnaires designed to measure his study effectiveness.

In actuality, the articles were persuasive communications selected from McGuire's (1964) communications on health practices. Two communications were used. One discussed the "harmful effects of chest X-rays" and the second discussed the "dangers of excessive tooth brushing." Each $S$ read only one of the communications. The communications were attributed to either a prestigeous medical journal or to a small rural newsletter. This attempted manipulation of credibility was apparently unsuccessful. There were no effects due to credibility, and it will not be discussed further. After reading the communication, the $S$ completed a 10 -item recall quiz over the article, a 7-item questionnaire designed to measure general reactions to the article, a mood adjective rating scale, and an opinion scale designed to measure the $S$ 's attitude. The opinion scale contained four items on each of several health issues, including both the experimental issue that the $S$ read and the second issue that he did not read. Thus, each $S$ provided both experimental and control opinion data on the two communications. After completing the scales, the $S$ returned to the "psychophysiology experiment," where he was debriefed and dismissed.

\section{RESULTS AND DISCUSSION}

The original design of the study included four factors, sex by fear by credibility by communications, each at two levels in a factorial design. No attempt was made to control birth order. The opinion means on 
Table I

Mean Attitude Scores

\begin{tabular}{lrrrr} 
& \multicolumn{2}{c}{ Males } & & Females \\
\cline { 2 - 5 } Birth Order & Low Fear & High Fear & Low Fear & High Fear \\
\hline Later Born & $8.60(5)$ & $32.43(7)$ & $27.75(8)$ & $13.43(7)$ \\
First Born & $19.43(7)$ & $11.20(5)$ & $38.75(4)$ & $19.80(5)$ \\
\hline
\end{tabular}

Note-The number of $S s$ in each condition is shown in parentheses.

the control issue did not differ across communications. Therefore, a difference score between each S's total opinion score on the experimental issue and the control issue was calculated to provide a sensitive measure of attitude change. The data were then analyzed as a fear by birth order design separately for each sex. The mean attitude change and frequency of $S s$ in each of the experimental conditions are shown in Table 1. As shown in Table 1, the pattern of the means was very different for males and females. For males, later-born Ss under high-fear conditions were more persuaded than were first-born Ss. However, the direction was reversed in the low-fear condition, with first-borns more persuaded than later-borns. The Fear by Birth Order interaction was significant $(F=5.58, \mathrm{df}=1 / 20, p<.03)$. Neither of the main effects was significant.

The results for males were almost identical to the results Helmreich, Kuiken, \& Collins (1968) found for their male Ss. In their study, as in the present study, later-born $\mathrm{Ss}$ under high fear showed considerably more change than any other group. Similarly, in their study, there was very little difference between first borns and later borns under low fear. In the present study, the difference between first borns and later borns under low fear is only half of the comparable difference in the high-fear condition.

When the results for females are considered, however, there is no evidence of an interaction $(F=.08, \mathrm{df}=1 / 20$, $p>.50$ ). Females in both birth-order conditions were more persuaded under low fear. The main effect of fear was significant $(F=4.28, \mathrm{df}=1 / 20, p<.05)$, even with the small number of first-born females in the low-fear condition. The main effect of birth order was not significant. Thus, females reacted to the situation very differently than did males.

An analysis of the recall scores indicated that there were no differences in learning between the experimental conditions for either sex. Also, there were no differences on any of the seven general evaluation rating items. A "fear" score was derived for each $S$ by summing the ratings on six of the mood words. This score was intended as a rough check on the fear manipulation. Analyses of these ratings did not reveal any differences between conditions. Perhaps the lack of differences on this measure was due to the fact that $S$ s had completed the other ratings first and were satiated with the rating task.

The results of the study confirm Helmreich's previous findings that a source of fear extraneous to the content of a communication does affect persuasibility. By implication, these results indicate that the generally positive relations found in studies using fear-arousing communications may be attributed to variation in the fear appeal rather than to changes in the content of the communication. At the same time, the present results indicate that the effects of fear on persuasibility are not simple. The interaction of birth order with fear for males implicates personality variables in the relationship, although it is unclear at present what those variables are. The results for females show an inverse relationship between persuasion and fear. Actually, the data for females might be
RONALD E. SMITH, University of Washington, Seattle, Wash. 98105, and BARRY L. MEADOW and THOMAS K. SISK, Purdue University, Lafayette, Ind. 47907

Ss, differing in the degree to which they were led to believe that a stranger's attitudes were similar to their own, observed the stranger (a confederate) in a verbal learning situation in which shock was supposedly administered for incorrect responses. The confederate's performance interpreted as supporting Janis \& Feshbach's (1953) defensive avoidance hypothesis. It appears that the search for a simple fear-arousal/persuasion relationship will not be successful. Very likely the joint effect of fear and (perhaps many) other interacting variables will have to be considered to make sense out of this area of research.

\section{REFERENCES}

HELMREICH, R, KUIKEN, D., \& COLLINS, B. Effects of stress and birth order on attitude change. Journal of Personality, 1968, 36, 466-473.

JANIS, I., \& IESHBACH, S. Effects of fear-arousing communications. Journal of Abnormal \& Social Psychology, 1953, 48, 78-92.

MoGUIRE, W. J. Inducing resistance to persuasion. In L. Berkowitz (Ed.), Advances in experimental social psychology. Vol. 1. New York: Academic Press, 1964. Pp. 191-229.

McGUIRE, W. J. Attitudes and opinions. Annual Review of Psychology, 1966, 17, 475-514.

McGUIRE, W. J. The nature of attitudes and attitude change. In G. Lindzey and E. Aronson (Eds.), The handbook of social psychology. (2nd ed.) Vol. 3. The individual in a social context. Reading, Mass: Addison-Wesiey, 1969. Pp. 136-314.

SIGALL, H., \& HELMREICH, R. Opinion change as a function of stress and communicator credibility. Journal of Experimental Social Psychology, 1969, 5, 70-78. NOTE.

1. We are grateful to Mary Catherine DeLattre who served as the second $E$.

\section{Attitude similarity, interpersonal attraction, and evaluative social perception}

was programmed so as to be the same for all Os. Attitude similarity was positively related to both pre-and postobservation attraction ratings. High similarity and high attraction $S s$ rated the stranger's performance significantly more favorably and also exhibited a tendency to rate the shock supposedly experienced by him as being more painful than did low similarity and at traction $S$ s.

Byrne (1969) has summarized a long series of studies indicating a positive linear 